\title{
Research on the Relationship Between Iron and Steel Production and Air Quality in Beijing - Tianjin - Hebei Region_Air Quality in Beijing and Tianjin as the Goal
}

\author{
Jian Li ${ }^{a}, Z e f a n J^{b}{ }^{b}$ \\ Tianjin University of Technology, Tianjin 300384, China; \\ alijian631219@163.com, b752526513@qq.com
}

Keywords: Air pollution; Beijing-Tianjin-Hebei region; Iron and steel industry; Correlation

\begin{abstract}
This paper mainly studies the effects of monthly production of iron and steel in eight cities in Hebei on the air quality of Beijing and Tianjin. First, this paper uses 10 cities to study whether iron and steel production has an impact on air quality, and the conclusion is that iron and steel production and air quality are correlated. Then, the linear regression of the corrected iron and steel production and the standardized air quality data is used to study the effect of steel production in eight cities of Hebei on the air quality of the two cities in Beijing and Tianjin respectively. The conclusion shows that the air quality of Beijing is closely related to the iron and steel production of Handan, and there is a positive correlation between the two variables.
\end{abstract}

\section{Introduction}

The primary goal is to solve the air pollution problem. Currently there are nearly 20,000 polluting enterprises in the Beijing-Tianjin-Hebei region, which mainly belong to coal, steel, and chemical industries. The steel industry is an important pillar industry of the national economy, and it is also a typical industry with high energy consumption, high emission, and high pollution. Hebei is the largest province of steel in China. Hebei Iron and Steel is one of the pillar industries of Hebei's economic development and an integral part of China's steel industry. In recent years, atmospheric pollution problems such as "smog" in North China have become increasingly serious, and a large amount of coal consumption in Hebei is one of the important causes of "smog". In 2012, about 26.6\% of sulfur dioxide and $40 \%$ of smoke and dust emissions in Hebei Province came from the steel industry. On October 15, 2013, the State Council issued the "Guiding Opinions on Resolving the Contradictory Problem of Serious Overcapacity", which emphasized that the key was to promote the structural adjustment of the steel industry in Shandong, Hebei, Liaoning, Jiangsu, Shanxi, and Jiangxi, and optimize the industrial layout. Total steel production capacity is more than 80 million tons. On November 6, 2013, the State Council approved the "Structure Adjustment Plan for the Hebei Iron and Steel Industry". The plan states that by the end of 2017, Hebei Province will eliminate 60,000 tons of steel production capacity.

\section{Model}

\subsection{Data Source}

Air Quality Index (AQI) data is from the People's Republic of China Department of Environmental Protection data center 2014-2016 daily real-time data and use Excel to find the average monthly value. According to the 《Environmental Quality Index (AQI) Technical Regulations (Trial) 》 issued by the Ministry of Environmental Protection of the People's Republic of China in 2012.

Steel production data from China Union Iron and Steel Network(http://www.custeel.com). The distance data of eight cities in Hebei to Beijing and Tianjin, are from Baidu map. Which Beijing selected Tian' a men Square as the end, Tianjin selected the government of Heping District as the end, measure and calculate the city each iron and steel enterprises to the two end points of the average distance, as the city to Beijing and Tianjin distance. 


\subsection{Build the Model}

\subsubsection{Correlation Between Iron and Steel Production and Air Quality in Each City}

(1) Correlation analysis

First, standardize the data of the air quality.

Then, use spss19.0 software to calculate the correlation coefficient and $\mathrm{P}$ value between steel production and air quality of each city, which given in table 1 . The results show that the $\mathrm{P}$ value of less than 0.05 in the cities of Tangshan, Shijiazhuang, Langfang, indicating that at 5\% level, Tangshan, Shijiazhuang, Langfang, the respective steel production and air quality are related. The correlation coefficient of Tangshan is -0.356 , which shows that the steel output and the air quality index show a negative weak linear correlation. Shijiazhuang' $\mathrm{s}$ is -0.523 , indicating that its steel production and air quality index showed a negative linear correlation. The correlation coefficient of Langfang is -0.57 , indicating that its steel output has negative linear correlation with air quality index. And the correlation coefficient between the respective steel production and the air quality index of the rest of the city is greater than 0.05 , and the absolute value of the correlation coefficient is close to zero, so there is no linear correlation.

Tab.1.Statistics on the correlation between steel production and air quality in each city

\begin{tabular}{llllllllllll}
\hline City & \multicolumn{3}{c}{ Bejing Tianjing Tangshan Handan $\begin{array}{l}\text { Shijia } \\
\text { zhuang }\end{array}$} & Chengde & \multicolumn{3}{l}{$\begin{array}{l}\text { Zhang } \\
\text { jiakou }\end{array}$} \\
\hline $\mathrm{r}$ & 0.078 & -0.224 & -0.356 & 0.293 & -0.523 & 0.249 & 0.180 & -0.570 & -0.139 & -0.089 \\
$\mathrm{P}$ Value & 0.680 & 0.188 & 0.033 & 0.083 & 0.001 & 0.143 & 0.293 & 0.000 & 0.419 & 0.606 \\
\hline
\end{tabular}

(2) Linear regression analysis

According to the conclusion of Table 1, it can be concluded that only the steel production of Tangshan, Shijiazhuang and Langfang has a significant linear correlation with the air quality. In order to further explore the relationship between the variables, linear regression, the rest of these cities do not carry out linear regression. Respectively, use Tangshan, Shijiazhuang, Langfang, the respective steel production as independent variables, the respective air quality as the dependent variable, then get on a linear regression analysis, the results shown in Table 2 . It can be concluded that the $P$ values of the two urban models in Tangshan and Langfang are all greater than 0.05 , indicating that the regression coefficient is not significant at the 5\% level. Shijiazhuang' s steel production coefficient and intercept corresponding to the $\mathrm{P}$ value is less than 0.05 , the coefficient at $5 \%$ level significantly, indicating that Shijiazhuang' $s$ iron and steel production and air quality index have a clear linear relationship, as shown on the below.

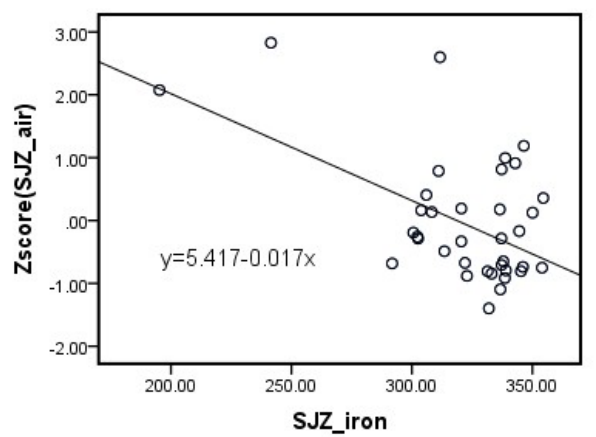

Fig.1.Regression diagram of Shijiazhuang' s Iron and Steel Production and Air Quality Index Tab.2.Tangshan, Shijiazhuang and Lang fang's respective iron and steel production and air quality index regressive relationship statistics

\begin{tabular}{ccccccc}
\hline City & \multicolumn{2}{c}{ Tangshan } & \multicolumn{2}{c}{ Shijiazhuang } & \multicolumn{2}{c}{ Langfang } \\
\hline Value & Coefficient & P Value & Coefficient & P Value & Coefficient & P Value \\
Intercept & 4.412 & 0.077 & 5.417 & 0.001 & 1.684 & 0.420 \\
Iron and Steel Production & -0.003 & 0.077 & -0.017 & 0.001 & -0.014 & 0.419 \\
$\mathrm{R}^{2}$ & 0.101 & & 0.252 & & 0.305 & \\
\hline
\end{tabular}




\subsubsection{Correlation Between Iron and Steel Production and Beijing - Tianjin Region's Air Quality}

(1) Correlation analysis

Standardize respectively the distance of the 8 cities to Beijing and Tianjin, then use the reciprocal of the distance as a correction factor to the 8 cities' iron and steel production correction, that is, Beijing and Tianjin, iron and steel production multiplied by the correction factor with the 8 cities' iron and steel production as their new production.

With the revised steel production of eight cities in Hebei and the air quality of Beijing to do the correlation analysis, the same reason, then with the air quality of Tianjin to do the correlation analysis, the results are shown in the following table.

The linear correlation with the air quality index of Beijing is the iron and steel production of Handan and Langfang because the corresponding $\mathrm{P}$ value is less than 0.05 , indicating that the correlation coefficient is significant at the 5\% level. The corresponding $\mathrm{P}$ values of the six cities in Tangshan, Shijiazhuang, Chengde, Zhangjiakou, Xingtai and Hengshui are all higher than 0.05, indicating that the iron and steel production in these six cities do not have a significant linear correlation with the Beijing air quality index at $5 \%$. The correlation coefficient between iron and steel production in Lang fang and Beijing' $\mathrm{s}$ air quality index is -0.423 , P value is 0.010 , indicating that the iron and steel production of Langfang has a weak correlation with the air quality index of Beijing. The correlation coefficient of Handan's iron and steel production and the air quality index of Beijing is $0.339, \mathrm{P}$ value is 0.043 , indicating that Handan's iron and steel production and the air quality index of Beijing showed a weak positive correlation.

The linear correlation with the Tianjin air quality index is the iron and steel production of Xingtai and Langfang, because the corresponding $\mathrm{P}$ value is less than 0.05 , indicating that the correlation coefficient is significant at the 5\% level. The corresponding $\mathrm{P}$ value of the other cities is greater than 0.05 , indicating that in the $5 \%$ level, the correlation coefficient is not significant. The correlation coefficient between iron and steel production in Langfang and Tianjin air quality index is $-0.570, \mathrm{P}$ value is 0 , indicating that the steel output of Langfang has a weak correlation with Tianjin' $\mathrm{s}$ air quality index, and the correlation is very significant. The correlation coefficient between the iron and steel production of Xingtai and the air quality index of Tianjin is -0.392 , $\mathrm{P}$ value is 0.018 , indicating that the iron and steel production of Xingtai has a weak negative correlation with Tianjin' $s$ air quality index, and the coefficient is significant.

Tab.3. Statistics on the correlation between corrected iron and steel production in each city and Beijing and Tianjin' s air quality

\begin{tabular}{cccccccccc}
\hline \multirow{2}{*}{ City } & Tangshan & Handan & $\begin{array}{c}\text { Shijia } \\
\text { zhuang }\end{array}$ & Chengde & $\begin{array}{c}\text { Zhang } \\
\text { jiakou }\end{array}$ & Langfang & Xingtai & Hengshui \\
\hline \multirow{2}{*}{ Beijing } & $\mathrm{r}$ & -0.271 & 0.339 & -0.332 & 0.062 & -0.145 & -0.423 & -0.136 & -0.002 \\
& P Value & 0.110 & 0.043 & 0.055 & 0.721 & 0.399 & 0.010 & 0.430 & 0.991 \\
\multirow{2}{*}{ Tianjin } & $\mathrm{r}$ & -0.299 & 0.264 & -0.262 & -0.110 & -0.134 & -0.570 & -0.392 & 0.047 \\
& P Value & 0.077 & 0.119 & 0.123 & 0.523 & 0.436 & 0.000 & 0.018 & 0.788 \\
\hline
\end{tabular}

(2) Linear regression analysis

According to the correlation analysis, the following linear regression analysis of these variables which with linear relationship. Then get table 4: 
Tab.4.Iron and steel production in each city and Beijing and Tianjin air quality index regression analysis of statistical tables

\begin{tabular}{|c|c|c|c|c|c|c|c|c|}
\hline \multirow{4}{*}{$\begin{array}{c}\text { Independent } \\
\text { variable } \\
\text { Intercept }\end{array}$} & \multicolumn{4}{|c|}{ AQI of Beijing } & \multicolumn{4}{|c|}{ AQI of Tianjin } \\
\hline & \multicolumn{2}{|c|}{$\begin{array}{l}\text { Handan's iron and } \\
\text { steel production }\end{array}$} & \multicolumn{2}{|c|}{$\begin{array}{l}\text { Langfang' s iron and } \\
\text { steel production }\end{array}$} & \multicolumn{2}{|c|}{$\begin{array}{l}\text { Xingtai' s iron and } \\
\text { steel production }\end{array}$} & \multicolumn{2}{|c|}{$\begin{array}{l}\text { Langfang's iron and } \\
\text { steel production }\end{array}$} \\
\hline & Coefficient & $\begin{array}{c}P \\
\text { Value }\end{array}$ & Coefficient & $\begin{array}{c}P \\
\text { Value }\end{array}$ & Coefficient & $\begin{array}{c}\mathrm{P} \\
\text { Value }\end{array}$ & Coefficient & $\begin{array}{r}\mathrm{P} \\
\text { Value }\end{array}$ \\
\hline & -9.006 & 0.043 & 1.530 & 0.013 & 4.743 & 0.019 & 2.064 & 0 \\
\hline Iron and steel & 2.846 & 0.043 & -1.031 & 0.010 & -13.161 & 0.018 & -0.632 & 0 \\
\hline $\mathrm{R}^{2}$ & 0.089 & & 0.155 & & 0.128 & & 0.305 & \\
\hline
\end{tabular}

It can be seen from Table 4 that the P values of the four models' coefficients are less than 0.05 , indicating that the model coefficients are significant at the $5 \%$ level, and the regression equation is obtained. However, considering the actual situation, in the four models, only Beijing' s air quality index and Handan's iron and steel production of this model is more fit the actual situation, that is, if Handan's iron and steel production increases, then Beijing' $s$ air quality index increases, that is, air quality deteriorates. The scatter plot of Handan' $s$ iron and steel production and Beijing' s air quality index shown below, there is a clear linear relationship between the two.

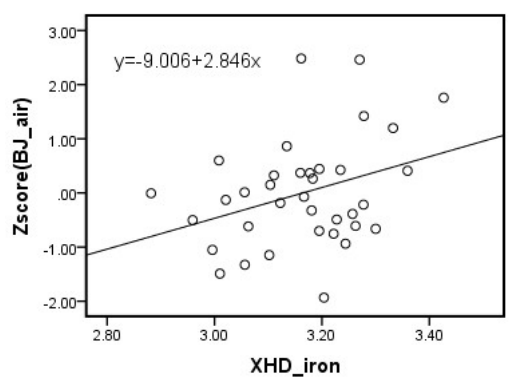

Fig.2.Regression diagram of Handan's iron and steel production and Beijing' s air quality index

\section{Conclusion and Advice}

Beijing's air quality index is more closely related to Handan's iron and steel production, and there is a positive correlation between the two variables, that is, if the iron and steel production of Handan is increased, the Beijing' s air quality index increases, which the air quality deteriorates.

The reasonable scale reduction of the steel industry in Hebei province will lead to a decline in the size of most of the heavy industry sectors, and, it should increase the reasonable compression and production reduction of the Handan' s iron and steel Industry. Then, control strictly the production process, strengthens the management of the enterprise, improves the management level. Finally, strengthen the supervision and assessment system of steel companies, strictly follow the national standards for production, and strictly control the quality of products. Once any companies and products that do not meet the standards are found, they should be promptly dealt with and ordered to stop production.

\section{References}

[1]. Hu Sun, Biao Qiao. Study on Problems in Beijing,Tianjin and Hebei Coordinated Industrial Development and Recommendations [J]. China Soft Science, 2015,07:68-74.

[2]. Cuimin Zhen. Study on Optimization Strategy of Hebei Steel Industrial Cluster Organization[J]. Science and Technology Management Research, 2012,32(01):159-161.

[3]. Ya Zhang. Eco-design of Steel Industry and Policy Options in China[J]. China Population, Resource and Environment, 2012,22(07):162-166. 